\title{
THE POWER INEQUALITY ON NORMED SPACES
}

\author{
by MICHAEL J. CRABB
}

(Received 17th February 1970)

Let $X$ be a complex normed space, with dual space $X^{\prime}$. Let $T$ be a bounded linear operator on $X$. The numerical range $V(T)$ of $T$ is defined as $\{f(T x): x \in X$, $\left.f \in X^{\prime},\|x\|=\|f\|=f(x)=1\right\}$, and the numerical radius $v(T)$ of $T$ is defined as $\sup \{|z|: z \in V(T)\}$. For a unital Banach algebra $A$, the numerical range $V(a)$ of $a \in A$ is defined as $V\left(T_{a}\right)$, where $T_{a}$ is the operator on $A$ defined by $T_{a} b=a b$. It is shown in (2, Chapter 1.2, Lemma 2) that $V(a)=\{f(a): f \in D(1)\}$, where $D(1)=\left\{f \in A^{\prime}:\|f\|=f(1)=1\right\}$.

For $X$ a Hilbert space, we have the power inequality $v\left(T^{n}\right) \leqq v(T)^{n}[\operatorname{see}(1)]$. In (3) it is shown that, for a normed space $X$,

$$
\left\|T^{n}\right\| \leqq n !(e / n)^{n} v(T)^{n} \quad(n=1,2, \ldots)
$$

and that $\left\{\left\|T^{n}\right\| / v(T)^{n}\right\}$ is bounded when $X$ has finite dimension. Glickfeld (4) has given an example of an operator $T$ for which $\|T\|=e v(T)$. The purpose of this paper is to prove the following theorem.

Theorem. There exists a Banach space $X$ and a non-zero bounded linear operator $T$ on $X$ such that

$$
\left\|T^{n}\right\|=n !(e / n)^{n} v(T)^{n} \quad(n=1,2, \ldots) .
$$

Corollary. For the operator of the theorem,

$$
v(T)^{n} \geqq n !\left(e^{n}-2\right) / n^{n} v(T)^{n}>v(T)^{n} \quad(n=2,3, \ldots) .
$$

Hence the constants in equality (1) are best possible, and $\left\|T^{n}\right\| / v(T)^{n}$ need not be bounded. Also, the power inequality does not extend to normed spaces.

Proof of Theorem. Let $n$ be a positive integer. Let $A_{n}$ be the algebra of elements

$$
\alpha_{0}+\alpha_{1} u+\ldots+\alpha_{n} u^{n} \quad\left(\alpha_{0}, \ldots, \alpha_{n} \in C\right)
$$

where $u^{n+1}=0$. For $a \in A_{n}$, define

$$
p(a)=\inf \left\{\sum_{k=1}^{m}\left|c_{k}\right| e^{\left|z_{k}\right|}: \sum_{k=1}^{m} c_{k} e^{z_{k} u}=a, c_{k}, z_{k} \in C, m \in P\right\} .
$$

Clearly $p$ is subadditive. To see that $p$ is an algebra-norm, let $a, a^{\prime} \in A$. For any $\varepsilon>0$, there exist a positive integer $m$, and $c_{i}, z_{i} \in C(i=1,2, \ldots, m)$ such that

$$
\sum_{i=1}^{m} c_{i} e^{z_{i} u}=a \text { and } \sum_{i=1}^{m}\left|c_{i}\right| e^{\left|z_{i}\right|}<p(a)+\varepsilon
$$


Similarly,

These give

$$
\sum_{j=1}^{m^{\prime}} c_{j}^{\prime} e^{z_{j}^{\prime \prime}}=a^{\prime} \quad \text { and } \quad \sum_{j=1}^{m^{\prime}}\left|c_{j}^{\prime}\right| e^{\left|z_{j}^{\prime}\right|}<p\left(a^{\prime}\right)+\varepsilon
$$

$$
\sum_{i=1}^{m} \sum_{j=1}^{m^{\prime}} c_{i} c_{j}^{\prime} e^{\left(z_{i}+z_{j}^{j}\right) u}=a a^{\prime}
$$

so that

$$
p\left(a a^{\prime}\right) \leqq \sum_{i=1}^{m} \sum_{j=1}^{m^{\prime}}\left|c_{i} c_{j}^{\prime}\right| e^{\left|z_{i}\right|+\left|z_{j}^{\prime}\right|}<(p(a)+\varepsilon)\left(p\left(a^{\prime}\right)+\varepsilon\right) .
$$

Since $\varepsilon$ is arbitrary, $p\left(a a^{\prime}\right) \leqq p(a) p\left(a^{\prime}\right)$. Now assume that $p(a)=0$, where $a=\alpha_{0}+\ldots+\alpha_{n} u^{n}$. From (2),

$$
\left|\alpha_{r}\right|=\left|\sum_{i=1}^{m} c_{i} z_{i}^{r} / r !\right| \leqq \sum_{i=1}^{m}\left|c_{i}\right| e^{\left|z_{i}\right|}<\varepsilon \quad(r=0,1, \ldots, n) .
$$

Since $\varepsilon$ is arbitrary, $a=0$.

Suppose that $u^{n}=\sum_{k=1}^{m} c_{k} e^{z_{k} u}$. Then, using the fact that $e^{t} \geqq(e / n)^{n} t^{n}(t \geqq 0)$, we have

$$
\sum_{k=1}^{m}\left|c_{k}\right| e^{\left|z_{k}\right|} \geqq \sum_{k=1}^{m}\left|c_{k}\right|(e / n)^{n}\left|z_{k}\right|^{n} \geqq(e / n)^{n}\left|\sum_{k=1}^{m} c_{k} z_{k}^{n}\right|=n !(e / n)^{n} .
$$

Hence $p\left(u^{n}\right) \geqq n !(e / n)^{n}$. Also, $v(u)=\sup _{z \neq 0}|z|^{-1} \log p\left(e^{z u}\right)$ by (2, Chapter 1.3, Theorem 4). Since $p\left(e^{z u}\right) \leqq e^{|z|}, v(u) \leqq 1$. From (1), we must in fact have $v(u)=1$ and $p\left(u^{n}\right)=n !(e / n)^{n}$.

Now let $A$ be the algebra of sequences $\left(a_{1}, a_{2}, \ldots\right)$, where $a_{n} \in A_{n}$ and $\left\{p\left(a_{n}\right)\right\}$ is bounded, with pointwise multiplication. For $a \in A$, let

$$
\|a\|=\sup \left\{p\left(a_{n}\right): n=1,2, \ldots\right\} \text {. }
$$

It may be proved that $A$ is complete, and so is a Banach algebra. Let $a$ be the element $\left(u_{1}, u_{2}, \ldots\right)$, where $u_{n}$ is the element $u$ of the algebra $A_{n}$ above. Then $\left\|e^{z a}\right\|=\sup \left\{p\left(e^{z u_{n}}\right): n=1,2, \ldots\right\} \leqq e^{\mid z !}$, so that $v(a) \leqq 1$. Also

$$
\left\|a^{n}\right\|=n !(e / n)^{n} \quad(n=1,2, \ldots)
$$

If we define, in the algebra $A_{n}$, a functional $f$ by

$$
f\left(\alpha_{0}+\alpha_{1} u+\ldots+\alpha_{n} u^{n}\right)=\alpha_{0}+\lambda_{1} \alpha_{1}+\ldots+\lambda_{n} \alpha_{n},
$$

then it is easily seen that $f \in D(1)$ if and only if

$$
\left|1+\lambda_{1} z+\ldots+\lambda_{n} z^{n} / n !\right| \leqq e^{|z|} \quad(z \in C)
$$

For $r=1,2, \ldots, n, f\left(u^{r}\right)=\lambda_{r} \in V\left(u^{r}\right)$, and so

$$
v\left(u^{r}\right)=\sup \left\{\left|\lambda_{r}\right|:\left|1+\lambda_{1} z+\ldots+\lambda_{n} z^{n} / n !\right| \leqq e^{|z|} \quad(z \in C)\right\} \text {. }
$$


It may be verified that, for $\lambda_{1}=\lambda_{2}=\ldots=\lambda_{n-1}=0$, and $\lambda_{n}=n !\left(e^{n}-2\right) / n^{n}$, $f \in D(1)$, so that $v\left(u^{n}\right) \geqq n !\left(e^{n}-2\right) / n^{n}$. Since $v\left(a^{n}\right) \geqq v\left(u^{n}\right)$, the corollary is established.

There remains the question of the best constants $k_{r}$ in $v\left(a^{r}\right) \leqq k_{r} v(a)^{r}$. From the above, we have $k_{r} \geqq r ! p_{r}$, where

$$
p_{r}=\sup \left\{\left|\lambda_{r}\right|:\left|1+\lambda_{1} z+\ldots+\lambda_{n} z^{n}\right| \leqq e^{|z|}(z \in C), n \geqq r\right\} .
$$

Also, for any unital Banach algebra $A, a \in A$ with $v(a)=1$, and $f \in D(1)$, we have

$$
\left|f\left(e^{z a}\right)\right|=\left|1+\ldots+z^{n} f\left(a^{n}\right) / n !+\ldots\right| \leqq e^{|z|} \quad(z \in C) .
$$

Hence $f\left(a^{r}\right) \leqq r ! q_{r}$, where

$$
q_{r}=\sup \left\{\left|\lambda_{r}\right|:\left|1+\ldots+\lambda_{r} z^{r}+\ldots\right| \leqq e^{|z|} \quad(z \in C)\right\} .
$$

Since this holds for any $f \in D(1), v\left(a^{n}\right) \leqq r ! q_{r}$. Hence $k_{r} \leqq r ! q_{r}$. To show that $k_{r}=r ! q_{r}$, it is enough to show that $p_{r}=q_{r}$. I am grateful to Professor J. G. Clunie for permission to publish his proof of the latter fact.

Lemma. $p_{n}=q_{n}(n=1,2, \ldots)$.

Proof. For $0<\varepsilon<1$, there exists a function $f(z)=\sum_{k=0}^{\infty} c_{k} z^{k}$ such that $|f(z)| \leqq e^{|z|}(z \in C)$, and $\left|c_{n}\right|>q_{n}-\varepsilon$. Then, by Cauchy's inequality and Parseval's theorem, for $N>n$,

$$
\begin{aligned}
\sum_{k=N+1}^{\infty}\left|c_{k}\right|(1-\varepsilon)^{k} r^{k} & \leqq\left(\sum_{k=N+1}^{\infty}\left|c_{k}\right|^{2} r^{2 k}\right)^{\frac{1}{2}}\left(\sum_{k=N+1}^{\infty}(1-\varepsilon)^{2 k}\right)^{\frac{1}{2}} \\
& \leqq \begin{cases}K r^{N+1} \varepsilon^{-1}(1-\varepsilon)^{N} & (0 \leqq r \leqq 1) \\
e^{r} \varepsilon^{-1}(1-\varepsilon)^{N} & (r \geqq 1)\end{cases}
\end{aligned}
$$

where $K$ is a constant. Let $g_{N}(z)=\sum_{k=0}^{N} c_{k}(1-\varepsilon)^{k} z^{k}$. For $z \in \dot{C}$,

$$
\left|g_{N}(z)\right| \leqq|f((1-\varepsilon) z)|+\sum_{k=N+1}^{\infty}\left|c_{k}\right|(1-\varepsilon)^{k}|z|^{k} \text {. }
$$

For $0 \leqq|z|=r \leqq 1$, provided $K \varepsilon^{-1}(1-\varepsilon)^{N} \leqq \varepsilon$, we have

so that

$$
e^{r}-e^{(1-\varepsilon) r} \geqq \varepsilon r \geqq K \varepsilon^{-1}(1-\varepsilon)^{N} r^{N+1},
$$

$$
\left|g_{N}(z)\right| \leqq e^{(1-z) r}+K \varepsilon^{-1}(1-\varepsilon)^{N} r^{N+1} \leqq e^{r}
$$

For $r \geqq 1$, provided $\varepsilon^{-1}(1-\varepsilon)^{N} \leqq\left(1-e^{-\ell}\right)$,

$$
\begin{aligned}
\left|g_{N}(z)\right| & \leqq e^{(1-\varepsilon) r}+\varepsilon^{-1}(1-\varepsilon)^{N} e^{r} \\
& \leqq e^{(1-\varepsilon) r}+\left(1-e^{-\varepsilon}\right) e^{r} \\
& \leqq e^{r}
\end{aligned}
$$


Hence, for $N$ sufficiently large, $\left|g_{N}(z)\right| \leqq e^{|z|}$. Therefore

$$
p_{n} \geqq(1-\varepsilon)^{n}\left|c_{n}\right|>(1-\varepsilon)^{n}\left(q_{n}-\varepsilon\right) .
$$

As this holds for any $\varepsilon$ with $0<\varepsilon<1, p_{n} \geqq q_{n}$. As $p_{n} \leqq q_{n}$, we have $p_{n}=q_{n}$.

It is of course not necessary to show that there exists a function $f$ for which $\left|c_{n}\right|=q_{n}$, but perhaps it is worth mentioning that Montel's theorem gives such an extremal function.

Corollary. $k_{n}=n ! p_{n}(n=1,2, \ldots)$.

This paper was written while the author held an S.R.C. research fellowship.

\section{REFERENCES}

(1) C. A. Berger, On the numerical range of an operator, Bull. Amer. Math. Soc. (to appear).

(2) F. F. Bonsall and J. DUNCAN, Numerical ranges of operators on normed spaces and of elements of normed algebras, London Math. Soc. Lecture Note Series, No. 2 (1971).

(3) M. J. CRABB, Numerical range estimates for the norms of iterated operators, Glasgow Math. J. (to appear).

(4) B. W. Guckfred, On an inequality of Banach algebra geometry and semiinner-product space theory, Notices Amer. Math. Soc. 15 (1968), 339-340.

UNIVERSITY OF ABERDEEN 